\title{
High triglyceride/HDL cholesterol ratio is associated with silent brain infarcts in a healthy population
}

\author{
Ki-Woong Nam ${ }^{1}$, Hyung-Min Kwon ${ }^{3}$, Han-Yeong Jeong ${ }^{1}$, Jin-Ho Park ${ }^{2 *}$, Hyuktae Kwon $^{2}$ and Su-Min Jeong ${ }^{2}$
}

\begin{abstract}
Background: Triglycerides (TG)/high-density lipoprotein (HDL) cholesterol ratio is a marker of small/dense low-density lipoprotein particles, which are closely associated with various metabolic and vascular diseases. However, the role of TG/HDL cholesterol ratio in cerebrovascular diseases has not been well studied. In this study, we evaluated the relationship between TG/HDL cholesterol ratio and the presence of silent brain infarct (SBI) in a neurologically healthy population.
\end{abstract}

Methods: We retrospectively evaluated consecutive participants in health check-ups between January 2006 and December 2013. SBI was defined as an asymptomatic, well-defined lesion with a diameter of $\geq 3 \mathrm{~mm}$ on T1- or T2-weighted images. TG/HDL cholesterol ratio was calculated after dividing absolute TG levels by absolute HDL cholesterol levels.

Results: Of 3172 healthy participants, 263 (8.3\%) had SBI lesions. In multivariate analysis, TG/HDL cholesterol ratio was independently associated with $\mathrm{SBI}$ (adjusted odds ratio $[\mathrm{aOR}]=1.16,95 \%$ confidence interval $[\mathrm{Cl}]=$ 1.00 to $1.34, P=0.047$ ). This association was prominent in males $(a \mathrm{OR}=1.23,95 \% \mathrm{Cl}=1.03$ to $1.48, P=0.021$ ), but not in females. In the analyses of the relationships between lipid parameters and SBI lesion burden, TG/ $\mathrm{HDL}$ cholesterol ratio was positively correlated, and total cholesterol/TG ratio was negatively correlated with SBI lesion burden, in dose-response manners ( $P$ for trend $=0.015$ and 0.002 , respectively).

Conclusions: The TG/HDL cholesterol ratio was positively associated with the prevalence of SBI in a neurologically healthy population.

Keywords: Triglycerides; High-density lipoprotein; Silent brain infarct; Lacune; Cerebral small vessel diseases; Metabolic syndrome

\section{Background}

Silent brain infarct (SBI) is a subclinical pathology that is commonly found prior to ischemic stroke, especially in the elderly $[1,2]$. Ischemic stroke often results in disabilities with limited neurological recoveries [3]. Therefore, it is important to evaluate modifiable risk factors for SBI and establish an early intervention prior to ischemic stroke. Several risk factors and possible pathophysiological mechanisms for SBI have been suggested (e.g., lipohyalinosis,

\footnotetext{
* Correspondence: kkolzzi0@gmail.com

${ }^{2}$ Department of Family Medicine, Seoul National University College of Medicine and Seoul National University Hospital, 101 Daehakno, Jongno-Gu, Seoul 03080, South Korea

Full list of author information is available at the end of the article
}

atherosclerosis, and endothelial dysfunction), [4-6] however, there is still a lack of knowledge in this area.

For stroke clinicians, serum cholesterol level is a wellknown risk factor. International guidelines recommend the control of lipid profiles, particularly low-density lipoprotein (LDL) levels $[7,8]$. Recently, investigators have paid attention to the role of LDL particle phenotypes, rather than their total amounts, in the development of vascular complications $[9,10]$. Small/dense LDL particles have atherogenic roles, while larger ones seem to have protective effects [11-14]. However, direct determination of the LDL phenotype is expensive and not yet standardized $[9,10,15]$. Thus, application in clinical practice is still premature. 
The size of LDL particles is inversely determined by circulating triglyceride (TG) and very low-density lipoprotein (VLDL) levels $[9,10]$. Using this nature, investigators can identify LDL phenotypes based on the ratio of TG and high-density lipoprotein (HDL), which has been confirmed in direct validation studies [9-12, 15, 16]. Similar to small/dense LDL particles, high TG/HDL cholesterol ratio is also associated with insulin resistance (IR), metabolic diseases, and cardio/cerebrovascular diseases [1721]. In this study, we evaluated the relationship between TG/HDL cholesterol ratio and the prevalence of SBI in a neurologically healthy population.

\section{Methods}

\section{Participants}

We retrospectively evaluated 3257 participants from a consecutive registry of routine health check-ups at the Seoul National University Hospital Health Promotion Center between January 2006 and December 2013. Brain magnetic resonance imaging (MRI), magnetic resonance angiography (MRA), and laboratory examinations were conducted in all participants. Among them, 64 participants who had a history of stroke or severe neurological deficit were excluded. Subjects with missing covariate data $(n=18)$ and those under 30 years of age $(n=3)$ were also excluded. Finally, a total of 3172 neurologically healthy participants were analyzed (Fig. 1). The current study was approved by the Institutional Review Board at the Seoul National University Hospital (IRB number: $\mathrm{H}$ 1502-026-647) and any data not published within the article will be available from the corresponding author upon reasonable request.

\section{Clinical assessment}

We evaluated demographic and metabolic factors, including age, sex, body mass index, hypertension, diabetes, hyperlipidemia, ischemic heart disease, current smoking,

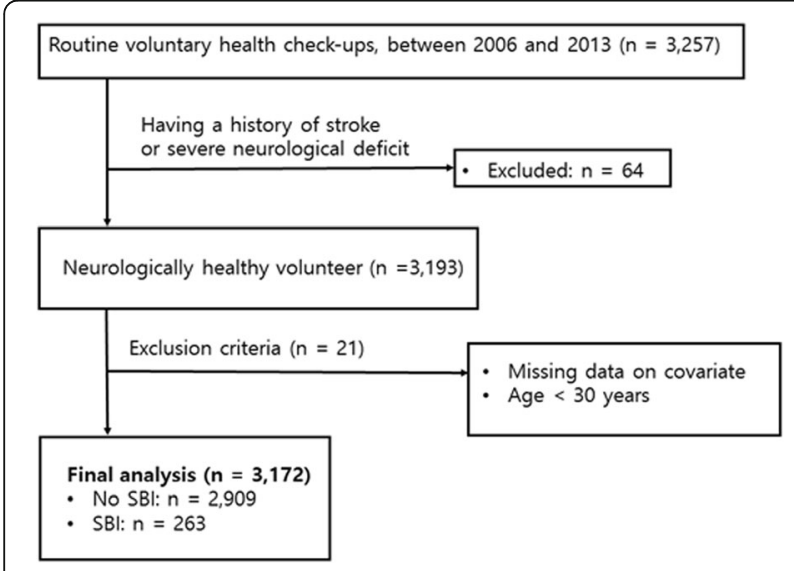

Fig. 1 Patients inclusion flow-chart current alcohol use, and use of antiplatelet, antihypertensive or statin medication [22]. Laboratory examinations, including glucose profiles, lipid profiles, high-sensitivity C-reactive protein (hs-CRP) levels, and white blood cell counts, were also conducted after $12 \mathrm{~h}$ of overnight fasting [22].

Lipid profiles included those of total cholesterol (TC), LDL cholesterol, HDL cholesterol, and TG. The TG/ HDL cholesterol ratio was calculated after dividing absolute TG levels by absolute HDL cholesterol levels in peripheral blood. Up to date, numerous novel indices have been developed from the classic lipid profiles, and they indicate additional information about LDL phenotype and vascular risk factors $[8,17,21]$. Thus, in addition to TG/HDL ratio, we also calculated TC/TG ratio which positively determines LDL particle size $[8,13]$.

\section{Radiological assessment}

All participants underwent brain MRI and MRA using a 1.5-Tesla MR scanner (Magnetom SONATA, Siemens, Munich, Germany or Signa, GE Healthcare, Milwaukee, WI, USA). The basic thickness of brain MRI was $5 \mathrm{~mm}$, and detailed acquisition parameters were as follows: T1weighted images (repetition time $[\mathrm{TR}] /$ echo time $[\mathrm{TE}]=$ $500 / 11 \mathrm{~ms}$ ); T2 fluid-attenuated inversion recovery images $(\mathrm{TR} / \mathrm{TE}=8800 / 127 \mathrm{~ms}) ;$ T2-weighted images $(\mathrm{TR} /$ $\mathrm{TE}=5000 / 127 \mathrm{~ms}) ; \mathrm{T} 2$-gradient echo images $(\mathrm{TR} / \mathrm{TE}=$ $57 / 20 \mathrm{~ms}$ ); and three-dimensional time-of-flight MRA images $(\mathrm{TR} / \mathrm{TE}=24 / 3.5 \mathrm{~ms}$, slice thickness $=1.2 \mathrm{~mm})$.

SBI was defined as an asymptomatic, well-defined lesion of $\geq 3 \mathrm{~mm}$ with the same signal characteristics as cerebrospinal fluid on T1- or T2-weighted images [1]. The burden of SBI lesions was classified as absent, single, or multiple. Intracranial atherosclerosis (ICAS) was defined as an occlusion or stenosis greater than $50 \%$ of an intracranial vessel on MRA [23]. All radiological markers were rated by two neurologists (K.-W.N. and H.-Y.J.). Disagreements were resolved by discussion with a third rater (H.-M.K.).

\section{Statistical analysis}

All statistical analyses were performed using SPSS version 23 (IBM SPSS, Chicago, IL, USA). To compare the baseline characteristics between participants with SBI and those without SBI, Student's $t$-test or the Mann-Whitney $U$-test were used for continuous variables, and the chisquared test or Fisher's exact test were used for categorical variables. Variables with $P<0.05$ in the univariate analysis and sex, LDL cholesterol were introduced as confounders in the multivariate logistic regression analysis. To eliminate the effect of lipid-lowering agents, we conducted additional sensitivity analysis after excluding 233 participants who were taking statin. Lipid profiles, especially TG and HDL cholesterol levels, are highly influenced by sex [19, 
24]. Therefore, we also conducted additional subgroup analyses in both male and female groups. Furthermore, to understand underlying pathophysiology, we compared various lipid parameter according to SBI lesion burden using the Kruskal-Wallis test, and the JonckheereTerpstra test. In this study, statistical significance was considered at $P<0.05$.

\section{Results}

A total of 3172 healthy subjects were assessed (median age: 56 years; male sex: $54.0 \%)$. SBI lesions were found in 263 (8.3\%) participants, and the median TG/HDL cholesterol ratio was 1.87 [1.23-3.02]. The baseline characteristics of the cohort are presented in Table 1. In univariate analyses, SBI (+) group was associated with age, hypertension, diabetes, antiplatelet medication, ICAS, and levels of fasting glucose, TC, LDL cholesterol, HDL cholesterol, TG, nonHDL cholesterol, TG/HDL cholesterol ratio, TC/TG ratio, and hs-CRP (Table 2).

In multivariate analysis to evaluate the possible predictors of SBI, TG/HDL cholesterol ratio (adjusted odds ratio $[\mathrm{aOR}]=1.16,95 \%$ confidence interval $[\mathrm{CI}]=1.00$ to $1.34, P=0.047$ ) remained a significant predictor of SBI, after adjustment for confounders (Table 3). Age and hypertension were also associated with SBI, independently of TG/HDL cholesterol ratio. Furthermore, this association was more prominent in males $(\mathrm{aOR}=1.23$, $95 \% \mathrm{CI}=1.03$ to $1.48, P=0.021$ ), but not in females. When we conducted additional sensitivity analysis to exclude the effect of statins, the close association between TG/HDL cholesterol ratio and SBI was confirmed (Additional file 1).

In the analyses of the relationships between lipid parameters and SBI lesion burden, TG/HDL cholesterol ratio was positively correlated $(P=0.046)$ and TC/TG ratio was negatively correlated $(P=0.007)$ with SBI lesion burden, even in dose-response manners ( $P$ for trend $=0.015$ and 0.002 , respectively) (Fig. 2). There was no significant correlation between TG $(P=0.113)$ or HDL cholesterol $(P=$ $0.059)$ and SBI lesion burden; however, they presented tendencies for dose-response relationships $(P$ for trend $=$ 0.037 and 0.026 , respectively).

Table 1 Baseline characteristics of the cohort $(n=3172)$

\begin{tabular}{|c|c|c|c|}
\hline & Total & $\begin{array}{l}\text { Male } \\
(n=1713)\end{array}$ & $\begin{array}{l}\text { Female } \\
(n=1459)\end{array}$ \\
\hline Age, y $[\mathrm{IQR}]$ & 56 [50-63] & 56 [50-63] & $57[51-63]$ \\
\hline Sex, male, n (\%) & $1713(54.0)$ & N/A & N/A \\
\hline Body mass index, kg/m² [IQR] & $24.03[22.11-25.96]$ & $24.48[22.73-26.35]$ & $23.47[21.53-25.43]$ \\
\hline Hypertension, n (\%) & $712(22.4)$ & $420(24.5)$ & $292(20.0)$ \\
\hline Diabetes, n (\%) & $437(13.8)$ & $390(16.9)$ & $147(10.1)$ \\
\hline Hyperlipidemia, n (\%) & $808(25.5)$ & $403(23.5)$ & $405(27.8)$ \\
\hline Ischemic heart disease, n (\%) & $124(3.9)$ & $73(4.3)$ & $51(3.5)$ \\
\hline Current smoking, n (\%) & $489(15.4)$ & $445(26.0)$ & $44(3.0)$ \\
\hline Current alcohol use, n (\%) & $1539(48.5)$ & $1148(67.0)$ & $391(26.8)$ \\
\hline On antiplatelet medication, n (\%) & $326(10.3)$ & $210(12.3)$ & $116(8.0)$ \\
\hline On antihypertensive, n (\%) & $699(22.0)$ & $371(21.7)$ & $328(22.5)$ \\
\hline On statin, n (\%) & $256(8.1)$ & $143(8.3)$ & $113(7.7)$ \\
\hline Fasting glucose, mg/dL [IQR] & $91[85-101]$ & $93[86-104]$ & 90 [84-99] \\
\hline Total cholesterol, mg/dL [IQR] & 198 [174-223] & $194[172-219]$ & 202 [178-227] \\
\hline LDL cholesterol, mg/dL [IQR] & 124 [101-147] & 123 [101-147] & 126 [102-148] \\
\hline HDL cholesterol, mg/dL [IQR] & 53 [45-63] & $49[42-58]$ & 57 [49-67] \\
\hline Triglycerides, mg/dL [IQR] & 100 [73-144] & 110 [78-159] & 91 [69-125] \\
\hline TG/HDL cholesterol ratio [IQR] & $1.87[1.23-3.02]$ & $2.21[1.43-3.56]$ & $1.56[1.09-2.42]$ \\
\hline TC/TG ratio [IQR] & $1.95[1.36-2.67]$ & $1.74[1.23-2.44]$ & $2.21[1.60-2.94]$ \\
\hline White blood cells, $\times 10^{3} / \mu \mathrm{L}[\mathrm{IQR}]$ & $5.31[4.40-6.37]$ & $5.61[4.66-6.82]$ & $5.03[4.15-5.98]$ \\
\hline hs-CRP, mg/dL [IQR] & $0.04[0.01-0.15]$ & $0.06[0.01-0.16]$ & $0.03[0.01-0.13]$ \\
\hline Silent brain infarct, n (\%) & $263(8.3)$ & $146(8.5)$ & $117(8.0)$ \\
\hline Intracranial atherosclerosis, n (\%) & $95(3.0)$ & $51(3.0)$ & $44(3.0)$ \\
\hline
\end{tabular}


Table 2 Differences of characteristics between patients with and without SBI

\begin{tabular}{|c|c|c|c|}
\hline & $\begin{array}{l}\text { No SBI } \\
(n=2909)\end{array}$ & $\begin{array}{l}\text { SBI } \\
(n=263)\end{array}$ & $P$-value \\
\hline Age, y [IQR] & $56[50-62]$ & $63[57-69]$ & $<0.001$ \\
\hline Sex, male, n (\%) & $1567(53.9)$ & $146(55.5)$ & 0.608 \\
\hline Body mass index, $\mathrm{kg} / \mathrm{m}^{2}[\mathrm{IQR}]$ & $24.00[22.12-25.95]$ & 24.24 [22.05-26.18] & 0.357 \\
\hline Hypertension, n (\%) & $619(21.3)$ & $93(35.4)$ & $<0.001$ \\
\hline Diabetes, n (\%) & $378(13.0)$ & $59(22.4)$ & $<0.001$ \\
\hline Hyperlipidemia, n (\%) & $737(25.4)$ & $71(27.0)$ & 0.562 \\
\hline Ischemic heart disease, n (\%) & $110(3.8)$ & $14(5.3)$ & 0.217 \\
\hline Current smoking, n (\%) & $455(15.6)$ & $34(12.9)$ & 0.243 \\
\hline Current alcohol use, n (\%) & 1419 (48.8) & $120(45.6)$ & 0.327 \\
\hline On antiplatelet medication, $\mathrm{n}(\%)$ & $285(9.8)$ & $41(15.6)$ & 0.003 \\
\hline On antihypertensive, $\mathrm{n}(\%)$ & $635(21.8)$ & $64(24.3)$ & 0.348 \\
\hline On statin, n (\%) & $233(8.0)$ & $23(8.7)$ & 0.675 \\
\hline Fasting glucose, mg/dL [IQR] & 91 [85-101] & 94 [85-109] & 0.003 \\
\hline Total cholesterol, mg/dL [IQR] & 198 [175-223] & $191[166-218]$ & 0.003 \\
\hline LDL cholesterol, mg/dL [IQR] & 125 [102-147] & 117 [90-147] & 0.009 \\
\hline HDL cholesterol, mg/dL [IQR] & $53[45-63]$ & $51[43-61]$ & 0.028 \\
\hline Triglycerides, mg/dL [IQR] & 99 [72-144] & $107[77-148]$ & 0.037 \\
\hline TG/HDL cholesterol ratio [IQR] & $1.85[1.22-2.98]$ & $2.12[1.31-3.38]$ & 0.016 \\
\hline $\mathrm{TC} / \mathrm{TG}$ ratio $[\mathrm{IQR}]$ & $1.97[1.39-2.69]$ & $1.74[1.20-2.49]$ & 0.002 \\
\hline White blood cells, $\times 10^{3} / \mu \mathrm{L}[\mathrm{IQR}]$ & $5.30[4.40-6.36]$ & $5.48[4.44-6.77]$ & 0.054 \\
\hline hs-CRP, mg/dL [IQR] & $0.04[0.01-0.15]$ & $0.07[0.01-0.17]$ & 0.039 \\
\hline Intracranial atherosclerosis, n (\%) & $80(2.8)$ & $15(5.7)$ & 0.007 \\
\hline
\end{tabular}

$L D L$ low-density lipoprotein, $H D L$ high-density lipoprotein, $T G$ triglyceride, $T C$ total cholesterol, $h s$-CRP high-sensitivity C-reactive protein

\section{Discussion}

In this study, we demonstrated that TG/HDL cholesterol ratio was positively associated with the prevalence of SBI in a neurologically healthy population. Since this association also occurred in a dose-response manner, our findings may suggest clues for the underlying pathophysiologic mechanisms.

Obviously, our main findings revealed that a pattern of "high-TG and low-HDL cholesterol" pattern may be harmful. This "atherogenic dyslipidemia" has been recently focused, because it is considered as a surrogate marker of small/dense LDL particles and IR status [11, 19, 25, 26]. Our results could be interpreted in two ways: first, as we mentioned, high TG/HDL cholesterol ratio indicates harmful small/dense LDL particles that could contribute to cerebrovascular diseases [12-14, 25]. Another index (i.e., TC/TG ratio), which positively reflects LDL particle size, [13] also confirmed this idea. Second, the hypertriglyceridemia itself could have harmful effects on cerebrovascular diseases, which is in line with previous studies $[27,28]$. Regardless of the interpretation, high TG levels, which are treated with a little different medication from that for high TC or LDL levels, should be controlled.
The exact mechanisms underlying the relationship between TG/HDL cholesterol ratio and SBI are unclear. However, we suggest several plausible explanations: first, high TG/HDL cholesterol ratio may indicate higher atherosclerosis burden. TG/HDL cholesterol ratio is closely associated with atherosclerosis regardless of their stenosis degree $[8,17,29,30]$. It can result from small/dense LDL particles which are susceptible to oxidation, leading to atherogenesis $[12,26]$. VLDL, which coexists with atherogenic dyslipidemia, also accelerates atherosclerosis by being taken into macrophages and developing foam cells [26]. Because advanced atherosclerosis can result in diffuse-hypoperfusion, extravasation of toxic metabolites into neural tissues, and occlusion of small arterioles, [22] high TG/HDL cholesterol may ratio be associated with the prevalence of SBI through higher atherosclerosis burden; second, inflammation and oxidative stress may play a role. TG/HDL cholesterol ratio indicates IR status, [17, 18, 29, $31,32]$ and then, it also means increased subclinical inflammation, disturbed metabolic status, and elevated sympathetic tone [31, 33]. This high inflammation burden promote downstream of lipid peroxidation and cellular/ DNA damage, leading to endothelial dysfunction/arterial 
Table 3 Multivariate analysis of possible predictors of silent brain infarct

\begin{tabular}{|c|c|c|c|c|}
\hline & Crude OR (95\% Cl) & $P$-value & Adjusted OR (95\% Cl) & $P$-value \\
\hline \multicolumn{5}{|l|}{ Total } \\
\hline $\mathrm{Age}^{\mathrm{a}}$ & 2.28 (1.98 to 2.63$)$ & $<0.001$ & 1.10 (1.09 to 1.12$)$ & $<0.001$ \\
\hline Sex & 1.07 (0.83 to 1.38) & 0.608 & $1.02(0.75$ to 1.39$)$ & 0.890 \\
\hline Hypertension & 2.02 (1.55 to 2.65 ) & $<0.001$ & $1.17(0.83$ to 1.65$)$ & 0.037 \\
\hline Diabetes & 1.94 (1.42 to 2.64$)$ & $<0.001$ & $1.31(0.90$ to 1.89$)$ & 0.157 \\
\hline On antiplatelet medication & 1.70 (1.19 to 2.43$)$ & 0.003 & $1.20(0.80$ to 1.79$)$ & 0.372 \\
\hline hs-CRP ${ }^{a}$ & $1.12(1.03$ to 1.21$)$ & 0.008 & 1.07 (0.96 to 1.18$)$ & 0.219 \\
\hline ICAS & 2.14 (1.21 to 3.77$)$ & 0.009 & 0.94 (0.44 to 2.00$)$ & 0.865 \\
\hline LDL cholesterol ${ }^{a}$ & 0.83 (0.71 to 0.96$)$ & 0.012 & 0.96 (0.83 to 1.13 ) & 0.637 \\
\hline TG/HDL cholesterol ratio ${ }^{a}$ & 1.13 (1.01 to 1.26$)$ & 0.030 & 1.16 (1.00 to 1.34$)$ & 0.047 \\
\hline \multicolumn{5}{|l|}{ Male } \\
\hline $\mathrm{Age}^{\mathrm{a}}$ & 2.44 (2.02 to 2.94) & $<0.001$ & $1.11(1.08$ to 1.14$)$ & $<0.001$ \\
\hline Hypertension & 2.27 (1.60 to 3.22 ) & $<0.001$ & 1.44 (0.92 to 2.24$)$ & 0.111 \\
\hline Diabetes & 1.69 (1.13 to 2.52$)$ & 0.010 & $1.14(0.71$ to 1.85$)$ & 0.587 \\
\hline On antiplatelet medication & 1.99 (1.30 to 3.07$)$ & 0.002 & 1.31 (0.79 to 2.16$)$ & 0.294 \\
\hline hs-CRPa & 1.17 (1.06 to 1.29$)$ & 0.002 & 1.08 (0.96 to 1.22$)$ & 0.206 \\
\hline ICAS & 2.06 (0.95 to 4.46) & 0.068 & 1.28 (0.49 to 3.32$)$ & 0.617 \\
\hline LDL cholesterol $^{a}$ & 0.74 (0.60 to 0.90$)$ & 0.003 & 0.94 (0.76 to 1.17$)$ & 0.590 \\
\hline TG/HDL cholesterol ratio ${ }^{\mathrm{a}}$ & 1.08 (0.94 to 1.24$)$ & 0.289 & 1.23 (1.03 to 1.48$)$ & 0.021 \\
\hline \multicolumn{5}{|l|}{ Female } \\
\hline $\mathrm{Age}^{\mathrm{a}}$ & 2.09 (1.69 to 2.59 ) & $<0.001$ & 1.09 (1.06 to 1.12$)$ & $<0.001$ \\
\hline Hypertension & 1.72 (1.13 to 2.62) & 0.012 & 0.88 (0.51 to 1.54$)$ & 0.656 \\
\hline Diabetes & 2.40 (1.47 to 3.93$)$ & $<0.001$ & $1.72(0.95$ to 3.11$)$ & 0.073 \\
\hline On antiplatelet medication & 1.22 (0.64 to 2.35) & 0.546 & $0.92(0.45$ to 1.86$)$ & 0.811 \\
\hline hs-CRP a & 1.01 (0.84 to 1.23$)$ & 0.898 & $1.02(0.82$ to 1.27$)$ & 0.848 \\
\hline ICAS & 2.24 (0.98 to 5.15$)$ & 0.057 & 0.67 (0.19 to 2.39$)$ & 0.532 \\
\hline LDL cholesterol ${ }^{a}$ & 0.95 (0.76 to 1.19) & 0.657 & $1.00(0.80$ to 1.26$)$ & 0.989 \\
\hline TG/HDL cholesterol ratio ${ }^{a}$ & 1.26 (1.03 to 1.53$)$ & 0.023 & 1.06 (0.82 to 1.36$)$ & 0.672 \\
\hline
\end{tabular}

hs-CRP high-sensitivity C-reactive protein, ICAS intracranial atherosclerosis, TG triglyceride, HDL high-density lipoprotein

${ }^{a}$ These variables were standardized by division by the standard deviation

stiffness. Supporting these ideas, several studies have reported a direct relationship between TG/HDL cholesterol ratio and arterial stiffness. We also found that subjects with higher TG/HDL cholesterol ratio had higher levels of inflammatory markers (e.g., hs-CRP and white blood cell counts) (Table 4) [14, 17]. Because endothelial dysfunction/arterial stiffness is one of leading causes of SBI development, [5] subclinical inflammation and endothelial dysfunction may provide a connection between TG/HDL cholesterol ratio and SBI prevalence; lastly, TG/HDL cholesterol ratio could be a simple surrogate marker of subjects who have numerous vascular risk factors. We already knew that TG/HDL cholesterol ratio is related to various metabolic risk factors that are also risk factors for SBI [17-19]. Thus, subjects with higher TG/HDL cholesterol ratio may have additional vascular risk factors that contribute to SBI (Table 4).

Interestingly, our results were more prominent in male participants. The exact reason for this sexual difference is unclear. However, we suggest several possible explanations: first, males had higher TG and lower HDL cholesterol values than those of females. Thus, the ratio of participants who had abnormal TG/HDL cholesterol ratio to normal ones may be prominent in males, and males had larger effect size. This could make more prominent association between TG/HDL cholesterol ratio and SBI. second, as we shown in Table 1, male participants had more frequent vascular risk factors than females, except for older age, and all of these metabolic and inflammatory factors were also closely related to 


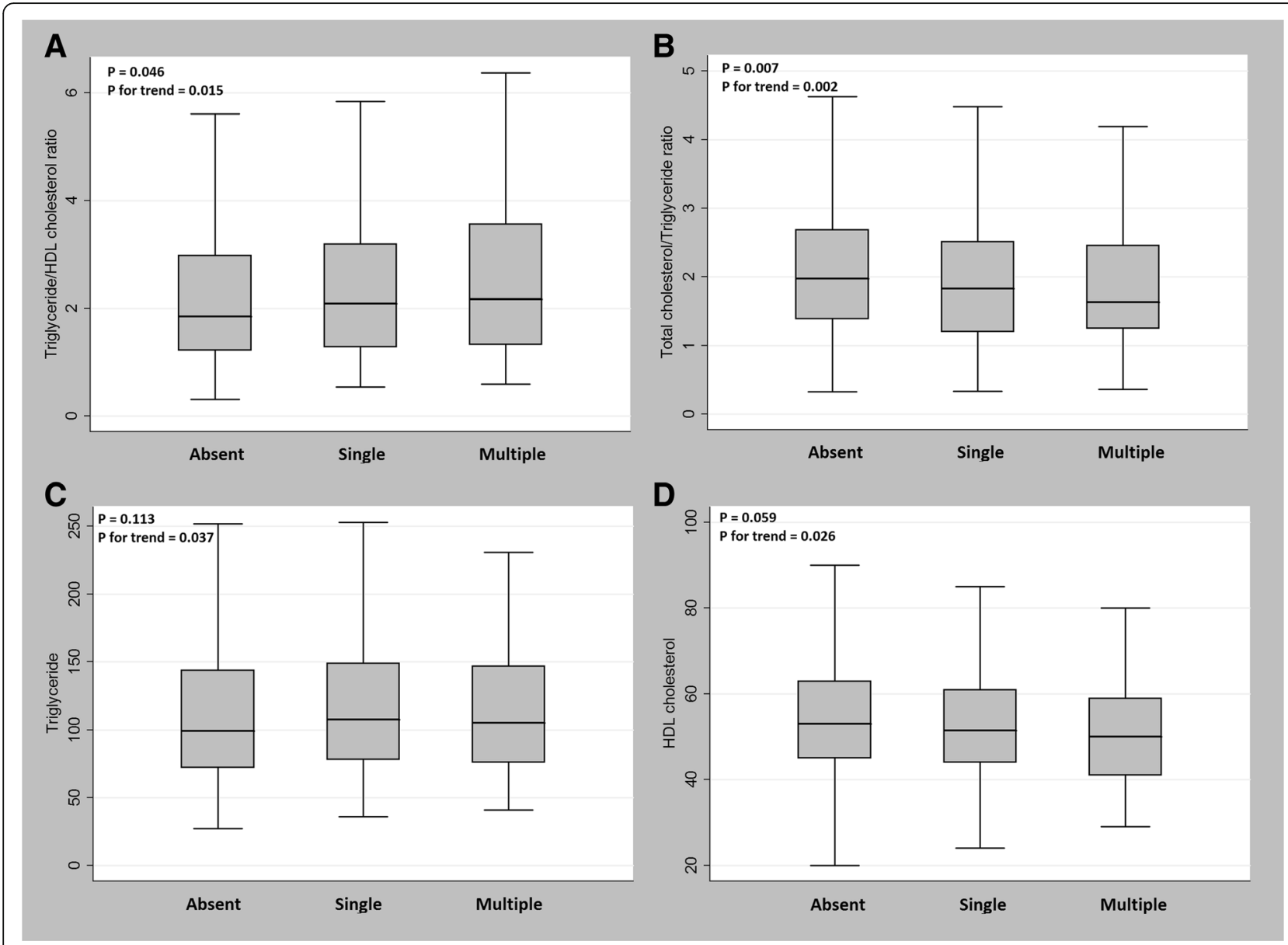

Fig. 2 The association between lipid parameters and SBI lesion burden. a TG/HDL cholesterol ratio correlated positively and b TC/TG ratio correlated negatively with SBI lesion burden, in dose-response manners (P for trend $=0.015$ and 0.002 , respectively). c TG and $\mathbf{d}$ HDL cholesterol also showed tendencies toward correlations with SBI lesion burden in dose-response manners, yet not significantly so

Table 4 Comparisons of risk factors according to TG/HDL cholesterol ratio teritles

\begin{tabular}{|c|c|c|c|c|}
\hline & $\begin{array}{l}\text { Tertile } 1 \\
(<1.42) \\
\end{array}$ & $\begin{array}{l}\text { Tertile } 2 \\
(1.42-2.56)\end{array}$ & $\begin{array}{l}\text { Tertile } 3 \\
(>2.56)\end{array}$ & $P$ for trend \\
\hline Number & 1057 & 1056 & 1059 & \\
\hline Age, y [IQR] & 55 [50-63] & 57 [52-63] & 56 [49-63] & 0.386 \\
\hline Sex, male, n (\%) & $421(39.7)$ & $555(52.7)$ & $737(69.7)$ & $<0.001$ \\
\hline Body mass index, kg/m² [IQR] & $22.92[21.11-24.80]$ & 24.14 [22.26-26.00] & 24.98 [23.37-26.93] & $<0.001$ \\
\hline Hypertension, n (\%) & $184(17.3)$ & $255(24.2)$ & $273(25.8)$ & $<0.001$ \\
\hline Diabetes, n (\%) & $99(9.3)$ & $143(13.6)$ & $195(18.4)$ & $<0.001$ \\
\hline Ischemic heart disease, n (\%) & $40(3.8)$ & $36(3.4)$ & $48(4.5)$ & 0.361 \\
\hline Current smoking, n (\%) & $86(8.1)$ & $124(11.8)$ & $279(26.4)$ & $<0.001$ \\
\hline Current alcohol use, n (\%) & $467(44.0)$ & $505(47.9)$ & $567(53.6)$ & $<0.001$ \\
\hline Fasting glucose, mg/dL [IQR] & 89 [82-97] & $92[85-101]$ & $95[87-105]$ & $<0.001$ \\
\hline White blood cells, $\times 10^{3} / \mu \mathrm{L}[\mathrm{IQR}]$ & $4.81[4.00-5.83]$ & $5.28[4.42-6.21]$ & $5.90[4.92-7.12]$ & $<0.001$ \\
\hline hs-CRP, mg/dL [IQR] & $0.02[0.01-0.11]$ & $0.05[0.01-0.15]$ & $0.09[0.01-0.18]$ & $<0.001$ \\
\hline
\end{tabular}


TG/HDL cholesterol ratio (Table 4). TG/HDL cholesterol ratio in male group might more clearly reflect vulnerable conditions underlying SBI development than female group. Last, another explanation is based on the distribution of the adipose tissue according to sex. Males have higher proportions of visceral adipose tissues, which are the sources of circulating TG, while females have a lot of subcutaneous adipose tissues with metabolically protective effects [34]. These biological discrepancies may explain the difference in TG/HDL cholesterol ratio, and its effect on SBI development.

Our study has several considerable limitations. First, it was designed as a retrospective, single-center study. We included a relatively large number of participants, and broadly evaluated their lipid profiles and brain MRI data. However, the possibility of selection bias still exists. Second, due to the nature of the cross-sectional analyses, we could not establish a causal relationship between TG/HDL cholesterol ratio and SBI. Further prospective randomized controlled studies are needed to identify causal relationships and underlying patho-mechanisms. Third, we could not directly measure small/dense LDL particle levels. If we included directly measured small/ dense LDL particle levels, we could investigate whether TG/HDL cholesterol ratio is only a surrogate marker for small/dense LDL particles or it also plays an individual role in SBI development. Fourth, although we have considered the effects of statin on our outcomes, other lipid-lowering agents such as fenofibrate may also influence the relationship between SBI and TG/HDL ratio. Last, SBI can not only be from atherosclerotic vascular diseases. Bias from other possible pathologies (e.g., vasculitis, dissection, cardioembolic sources, hypercoagulability) should be considered.

\section{Conclusion}

A high TG/HDL cholesterol ratio may be a risk factor for the prevalence and burden of SBI lesions in a neurologically healthy population. Because SBI is a risk factor for subsequent ischemic stroke, [2] our simple, inexpensive, but efficient method could identify modifiable high-risk group which requires early intervention. However, our findings should be confirmed with further prospective studies.

\section{Additional file}

Additional file 1: Multivariate analysis of possible predictors of silent brain infarct, excluding patients with statin uset $(n=2916)$. (DOCX $15 \mathrm{~kb})$

\section{Abbreviations}

HDL: High-density lipoprotein; hs-CRP: High-sensitivity C-reactive protein; ICAS: Intracranial atherosclerosis; IR: Insulin resistance; LDL: Low-density lipoprotein; SBI: Silent brain infarct; TC: Total cholesterol; TE: Echo time; TG: Triglyceride; TR: Repetition time; VLDL: Very low-density lipoprotein

\section{Acknowledgements}

None.

Authors' contributions

Conceptualization: K-WN, H-MK, J-HP. Data curation:K-WN,H-YJ, HTK, S-MJ. Formal analysis: K-WN, H-MK. Writing: K-WN, J-HP Supervision: H-MK, J-HP. All authors read and approved the final manuscript.

Funding

None.

Availability of data and materials

The datasets during and/or analyzed during the current study available from the corresponding author on reasonable request.

Ethics approval and consent to participate

The current study was approved by the Institutional Review Board at the Seoul National University Hospital (IRB number: H-1502-026-647). Because we used only recorded medical data without any intervention, the IRB at our center approved the study and waived the requirement for informed consent.

Consent for publication

Not applicable.

\section{Competing interests}

Hyung-Min Kwon is an editorial board member of BMC Neurology.

\section{Author details}

${ }^{1}$ Department of Neurology, Seoul National University College of Medicine and Seoul National University Hospital, Seoul, South Korea. ${ }^{2}$ Department of Family Medicine, Seoul National University College of Medicine and Seoul National University Hospital, 101 Daehakno, Jongno-Gu, Seoul 03080, South Korea. ${ }^{3}$ Department of Neurology, Seoul National University College of Medicine and Seoul Metropolitan Government-Seoul National University Boramae Medical Center, Seoul, South Korea.

Received: 15 March 2019 Accepted: 20 June 2019

Published online: 02 July 2019

\section{References}

1. Wardlaw JM, Smith EE, Biessels GJ, Cordonnier C, Fazekas F, Frayne R, Lindley RI, O'Brien JT, Barkhof F, Benavente OR. Neuroimaging standards for research into small vessel disease and its contribution to ageing and neurodegeneration. Lancet Neurol. 2013;12(8):822-38.

2. Kim BJ, Lee $\mathrm{S}-\mathrm{H}$. Prognostic impact of cerebral small vessel disease on stroke outcome. J Stroke. 2015;17(2):101.

3. Weimar C, Kurth T, Kraywinkel K, Wagner M, Busse O, Haberl RL, Diener H-C. Assessment of functioning and disability after ischemic stroke. Stroke. 2002; 33(8):2053-9.

4. Inoue K, Matsumoto M, Shono T, Toyokawa S, Moriki A. Increased intima media thickness and atherosclerotic plaques in the carotid artery as risk factors for silent brain infarcts. J Stroke Cerebrovasc Dis. 2007;16(1):14-20.

5. Hassan A, Hunt BJ, O'sullivan M, Parmar K, Bamford JM, Briley D, Brown MM, Thomas DJ, Markus HS. Markers of endothelial dysfunction in lacunar infarction and ischaemic leukoaraiosis. Brain. 2003;126(2):424-32.

6. Wardlaw J. Blood-brain barrier and cerebral small vessel disease. J Neurol Sci. 2010;299(1-2):66-71.

7. Powers WJ, Rabinstein AA, Ackerson T, Adeoye OM, Bambakidis NC, Becker K, Biller J, Brown M, Demaerschalk BM, Hoh B. 2018 guidelines for the early management of patients with acute ischemic stroke: a guideline for healthcare professionals from the American Heart Association/American Stroke Association. Stroke. 2018;49(3):e46-e110.

8. Bang O, Saver J, Liebeskind D, Pineda S, Ovbiagele B. Association of serum lipid indices with large artery atherosclerotic stroke. Neurology. 2008;70(11):841-7.

9. PLd L, Favarato D, Faria-Neto Junior JR, Lemos P, Chagas ACP. High ratio of triglycerides to $\mathrm{HDL}$-cholesterol predicts extensive coronary disease. Clinics. 2008;63(4):427-32

10. Boizel R, Benhamou PY, Lardy B, Laporte F, Foulon T, Halimi S. Ratio of triglycerides to $\mathrm{HDL}$ cholesterol is an indicator of LDL particle size in 
patients with type 2 diabetes and normal HDL cholesterol levels. Diabetes Care. 2000;23(11):1679-85.

11. Cabrera MAS, de Andrade SM, Mesas AE. A prospective study of risk factors for cardiovascular events among the elderly. Clin Interv Aging. 2012;7:463.

12. Frohlich J, Dobiášová M. Fractional esterification rate of cholesterol and ratio of triglycerides to $\mathrm{HDL}$-cholesterol are powerful predictors of positive findings on coronary angiography. Clin Chem. 2003;49(11):1873-80.

13. Yoshida A, Kouwaki M, Matsutani Y, Fukuchi Y, Naito M. Usefulness of serum total cholesterol/triglyceride ratio for predicting the presence of small, dense LDL. J Atheroscler Thromb. 2004;11(4):215-9.

14. Urbina EM, Khoury PR, McCoy CE, Dolan LM, Daniels SR, Kimball TR. Triglyceride to HDL-C ratio and increased arterial stiffness in children, adolescents, and young adults. Pediatrics. 2013;131(4):e1082-90. https://doi. org/10.1542/peds.2012-1726.

15. Bhalodkar NC, Blum S, Enas EA. Accuracy of the ratio of triglycerides to high-density lipoprotein cholesterol for predicting low-density lipoprotein cholesterol particle sizes, phenotype $B$, and particle concentrations among Asian Indians. Am J Cardiol. 2006;97(7):1007-9.

16. Dobiásová $\mathrm{M}$, Frohlich J. The plasma parameter log (TG/HDL-C) as an atherogenic index: correlation with lipoprotein particle size and esterification rate inapob-lipoprotein-depleted plasma (FERHDL). Clin Biochem. 2001;34(7):583-8.

17. Pacifico L, Bonci E, Andreoli G, Romaggioli S, Di Miscio R, Lombardo C, Chiesa C. Association of serum triglyceride-to-HDL cholesterol ratio with carotid artery intima-media thickness, insulin resistance and nonalcoholic fatty liver disease in children and adolescents. Nutr Metab Cardiovasc Dis. 2014;24(7):737-43.

18. Salazar MR, Carbajal HA, Espeche WG, Aizpurúa M, Maciel PM, Reaven GM. Identification of cardiometabolic risk: visceral adiposity index versus triglyceride/HDL cholesterol ratio. Am J Med. 2014;127(2):152-7.

19. Hermans MP, Ahn SA, Rousseau MF. The atherogenic dyslipidemia ratio [log (TG)/HDL-C] is associated with residual vascular risk, beta-cell function loss and microangiopathy in type 2 diabetes females. Lipids Health Dis. 2012;11(1):132.

20. Lamarche B, Després J-P, Moorjani S, Cantin B, Dagenais GR, Lupien P-J. Triglycerides and HDL-cholesterol as risk factors for ischemic heart disease. Results from the Quebec cardiovascular study. Atherosclerosis. 1996;119(2):235-45.

21. Deng QW, Wang H, Sun CZ, Xing FL, Zhang HQ, Zuo L, Gu ZT, Yan FL. Triglyceride to high-density lipoprotein cholesterol ratio predicts worse outcomes after acute ischaemic stroke. Eur J Neurol. 2017;24(2):283-91.

22. Nam K-W, Kwon H-M, Jeong H-Y, Park J-H, Kim SH, Jeong S-M, Yoo TG, Kim $\mathrm{S}$. Cerebral white matter hyperintensity is associated with intracranial atherosclerosis in a healthy population. Atherosclerosis. 2017;265:179-83.

23. Chimowitz MI, Kokkinos J, Strong J, Brown MB, Levine SR, Silliman S, Pessin MS, Weichel E, Sila CA, Furlan AJ, Kargman DE, Sacco RL, Wityk RJ, Ford G, Fayad PB, for the Warfarin-Aspirin Symptomatic Intracranial Disease Study Group. Warfarin-Aspirin Symptomatic Intracranial Disease (WASID) Trial: final results, Neurology. 1995;45(8):1488-93.

24. O'meara JG, Kardia SL, Armon JJ, Brown CA, Boerwinkle E, Turner ST. Ethnic and sex differences in the prevalence, treatment, and control of dyslipidemia among hypertensive adults in the GENOA study. Arch Intern Med. 2004;164(12):1313-8.

25. Bittner V, Johnson BD, Zineh I, Rogers WJ, Vido D, Marroquin OC, BaireyMerz CN, Sopko G. The TG/HDL cholesterol ratio predicts all cause mortality in women with suspected myocardial ischemia a report from the Women's ischemia syndrome evaluation (WISE). Am Heart J. 2009;157(3):548.

26. Mazza A, Tikhonoff V, Schiavon L, Casiglia E. Triglycerides+ high-densitylipoprotein-cholesterol dyslipidaemia, a coronary risk factor in elderly women: the CArdiovascular STudy in the ELderly. Intern Med J. 2005;35(10):604-10.

27. Freiberg JJ, Tybjærg-Hansen A, Jensen JS, Nordestgaard BG. Nonfasting triglycerides and risk of ischemic stroke in the general population. Jama. 2008:300(18):2142-52.

28. Varbo A, Nordestgaard BG, Tybjærg-Hansen A, Schnohr P, Jensen GB, Benn M. Nonfasting triglycerides, cholesterol, and ischemic stroke in the general population. Ann Neurol. 2011;69(4):628-34.

29. Masson W, Siniawski D, Lobo M, Molinero G, Huerín M. Association between triglyceride/HDL cholesterol ratio and carotid atherosclerosis in postmenopausal middle-aged women. Endocrinol Nutr. 2016;63(7):327-32.

30. Masley SC, Roetzheim R, Masley LV, McNamara T, Schocken DD. Emerging risk factors as markers for carotid intima media thickness scores. J Am Coll Nutr. 2015;34(2):100-7.
31. Shishehbor MH, Hoogwerf BJ, Lauer MS. Association of triglyceride-to-HDL cholesterol ratio with heart rate recovery. Diabetes Care. 2004;27(4):936-41.

32. González-Chávez A, Simental-Mendía LE, Elizondo-Argueta S. Elevated triglycerides/HDL-cholesterol ratio associated with insulin resistance. Cir Cir. 2011;79(2):126-31

33. Lee JE, Shin DW, Yun JM, Kim SH, Nam Y-S, Cho B, Lim J-S, Jeong H-Y, Kwon H-M, Park J-H. Insulin resistance is a risk factor for silent lacunar infarction. Stroke. 2016;47(12):2938-44.

34. Golan R, Shelef I, Rudich A, Gepner Y, Shemesh E, Chassidim Y, HarmanBoehm I, Henkin Y, Schwarzfuchs D, Avraham SB. Abdominal superficial subcutaneous fat: a putative distinct protective fat subdepot in type 2 diabetes. Diabetes Care. 2012;35(3):640-7.

\section{Publisher's Note}

Springer Nature remains neutral with regard to jurisdictional claims in published maps and institutional affiliations.
Ready to submit your research? Choose BMC and benefit from:

- fast, convenient online submission

- thorough peer review by experienced researchers in your field

- rapid publication on acceptance

- support for research data, including large and complex data types

- gold Open Access which fosters wider collaboration and increased citations

- maximum visibility for your research: over $100 \mathrm{M}$ website views per year

At BMC, research is always in progress.

Learn more biomedcentral.com/submissions 